\title{
Simulated radiative forcing from contrails and contrail cirrus
}

\author{
C.-C. Chen and A. Gettelman
}

National Center for Atmospheric Research, P.O. Box 3000, Boulder, CO 80307-3000, USA

Correspondence to: C.-C. Chen (cchen@ucar.edu)

Received: 6 March 2013 - Published in Atmos. Chem. Phys. Discuss.: 24 April 2013

Revised: 31 October 2013 - Accepted: 11 November 2013 - Published: 20 December 2013

\begin{abstract}
A comprehensive general circulation model including ice supersaturation is used to estimate the climate impact of aviation induced contrails. The model uses a realistic aviation emissions inventory for 2006 to initiate contrails, and allows them to evolve consistently with the model hydrologic cycle.

The radiative forcing from linear contrails is very sensitive to the diurnal cycle. For linear contrails, including the diurnal cycle of air traffic reduces the estimated radiative forcing by $29 \%$, and for contrail cirrus estimates, the radiative forcing is reduced by $25 \%$. Estimated global radiative forcing from linear contrails is $0.0031 \pm 0.0005 \mathrm{Wm}^{-2}$. The linear contrail radiative forcing is found to exhibit a strong diurnal cycle. The contrail cirrus radiative forcing is less sensitive to the diurnal cycle of flights. The estimated global radiative forcing from contrail cirrus is $0.013 \pm 0.01 \mathrm{Wm}^{-2}$. Over regions with the highest air traffic, the regional effect can be as large as $1 \mathrm{Wm}^{-2}$.
\end{abstract}

\section{Introduction}

Aircraft effects on clouds have significant impacts on climate (Lee et al., 2010; Burkhardt et al., 2010). When aircraft exhaust mixes with ambient air, liquid drops may form and freeze if the ambient air is cold and the humidity is high (Schmidt, 1941; Appleman, 1953), forming "condensation trails" or contrails, behind an aircraft. These line-shaped cirrus, the so-called linear contrails, may persist and take up water vapor from ambient air if the air is supersaturated with respect to ice. Persistent contrails may last minutes up to several hours (Minnis et al., 1998). Additional cloudiness beyond line-shaped contrails may be induced due to the spreading and shearing of contrails, known as contrail cirrus (Schumann and Wendling, 1990; Minnis et al., 1998).
Like natural cirrus, contrails have a radiative forcing effect on climate (Meerkötter et al., 1999; Marquart and Mayer, 2002), cooling in the shortwave by reflecting radiation to space, but heating in the longwave due to a low emission temperature. The longwave effect is thought to dominate for these clouds on a long-term average (Dietmüller et al., 2008; Rap et al., 2010). Estimates of radiative forcing associated with linear contrails range from 2 to 10 milliwatts per square meter $\left(\mathrm{m} \mathrm{Wm}^{-2}\right)$ (see summary in Lee et al., 2010). The uncertainty mainly results from the coverage and optical depth of contrails (Lee et al., 2010). Some studies (Myhre and Stordal, 2001; Stuber and Forster, 2006, 2007; Frömming et al., 2011; Newinger and Burkhardt, 2012) showed that the diurnal cycle of air traffic can also affect contrail radiative forcing. Stuber and Forster (2007) found that $60 \%$ of the global mean contrail radiative forcing was attributed to night flights even though they only accounted for $40 \%$ of the distance travelled by aircraft, and Newinger and Burkhardt (2012) reported $54 \%$ and $63 \%$ of the net contrail radiative forcing over the US and western Europe, respectively, was due to night flights.

Uncertainties in assessing the radiative forcing due to contrail cirrus are even higher. It is routinely observed that lineshaped contrails subsequently shear and spread after formation, termed contrail cirrus, and the additional cloudiness due to spreading may increase by a factor of 1.8 (Minnis et al., 2004). Larger spreading factors were reported by a recent study by Burkhardt and Kärcher (2011) in which they found an estimated radiative forcing of $31 \mathrm{~m} \mathrm{Wm}^{-2}$ for contrail cirrus by numerical simulations of a general circulation model (GCM) using a separate contrail cloud class.

In this study, the radiative forcing of linear contrails and contrail cirrus is assessed by using the Community Atmosphere Model version 5 (CAM5), of the National Center for Atmospheric Research (NCAR) Community Earth System 
Model (CESM). We employ an integrated approach to contrails by treating them as part of the model hydrologic cycle. This is possible because CAM5 now includes ice supersaturation and can simulate the key formulation and evolution process of contrails. A detailed aviation emissions inventory is incorporated into CAM5, and the importance of the consideration of the daily cycle of flights is examined by using aircraft emissions averaged on an hourly, daily, and monthly basis. The model and experimental design are described in Sect. 2, results are presented in Sect. 3, and discussions are in Sect. 4.

\section{Methodology}

\subsection{Model description}

This work uses CAM version 5 (Gettelman et al., 2010; Neale et al., 2010). The model includes a detailed treatment of cloud liquid and ice microphysics (Morrison and Gettelman, 2008), including a representation of particle size distributions, a detailed mixed phase with a representation of water uptake onto ice (the Bergeron-Findeisen process) and ice supersaturation (Gettelman et al., 2010). This is coupled to a consistent radiative treatment of ice clouds, and an aerosol model that includes particle effects on liquid and ice clouds (Liu et al., 2012). Critical for contrail formation, CAM5 can simulate the mean relative humidity and reproduce the distribution of the frequency of ice supersaturation in the upper troposphere and lower stratosphere (UTLS) (Chen et al., 2012) as observed from the Atmospheric Infrared Sounder (AIRS) satellite (Gettelman et al., 2006), including the hemispheric asymmetry of higher frequency of supersaturation at Southern Hemisphere midlatitudes.

\subsection{Contrail parameterization}

The contrail parameterization used is described in detail by Chen et al. (2012). The parameterization follows the Schmidt-Appleman criteria (Schmidt, 1941; Appleman, 1953): persistent contrails form if the ambient air temperature is below a critical temperature (Schumann, 1996) and the relative humidity is above ice supersaturation. When contrails are triggered, ambient water vapor above ice supersaturation within the volume swept by the aircraft is added to condensate. The volume is a product of the flight path distance and a cross-sectional area, assumed to be $300 \mathrm{~m} \times 300 \mathrm{~m}$ (Chen et al., 2012). Ice particles within the contrails are assumed to be spherical and have an initial diameter of $10 \mu \mathrm{m}$ (Schröder et al., 2000). The assumption on the particle shape and size has a significant impact on the contrail radiative forcing and will be discussed further in Sect. 3.2. The enhancement of cloud fraction due to formation of persistent contrails is equal to the contrail ice mixing ratio, attributed to the aircraft water vapor emissions and the ambient humidity, divided by an assumed empirical value for the in-cloud ice water content (ICIWC) (Schumann, 2002). The additional cloud fraction within each grid cell due to the presence of contrails is thus the exact fractional volume of contrails. Chen et al. (2012) demonstrated that this contrail parameterization was able to produce a reasonable spatial and seasonal distribution of contrails compared to observations, but the amount of contrail coverage is substantially lower than previous studies (Myhre and Stordal, 2001; Stuber and Forster, 2007; Rap et al., 2010; Frömming et al., 2011) due to the assumption of a $30 \mathrm{~min}$ lifetime for all contrails.

Coverage is also lower because the coarse $(\approx 1 \mathrm{~km})$ vertical grid spacing permits no vertical variation, and contrails in a grid box are "stacked" in the vertical. This results in small horizontal coverage but a corresponding thicker optical depth. Cloud fractions given in Table 2 of Chen et al. (2012) are, thus, not equivalent to cloud cover published in previous literature, be it simulated (e.g., Frömming et al., 2011) or observed (e.g., Duda et al., 2013) cover. However, we will demonstrate that the grid-box average optical depth and radiative forcing using this method are consistent with other work.

Chen et al. (2012) demonstrated that this contrail parameterization is sensitive to the initial ice particle size assumed and the cross-sectional area of contrails. The volume of contrails upon formation determines how much ambient humidity from the supersaturated region is taken into the contrails. These uncertainties were examined in Chen et al. (2012). For example, use of a more moderate ice particle size in contrail initialization will enhance ice number concentration and reflectance. A reduction of the cross-sectional area in contrail initialization will decrease the amount of ice mass in contrails and the contrail coverage. Chen et al. (2012) found a reduction of the cross-sectional area from $300 \mathrm{~m} \times 300 \mathrm{~m}$ to $100 \mathrm{~m} \times 100 \mathrm{~m}$ results in a decrease in ice mass by a factor of 4 and a decrease in contrail coverage by a factor of 2 .

\subsection{Modeling framework}

Previous estimates on the globally averaged contrail radiative forcing indicated that the magnitude of the forcing associated with linear contrails was less than $10 \mathrm{~m} \mathrm{Wm}^{-2}$ (Lee et al., 2010), and the radiative forcing of contrail cirrus could reach $31 \mathrm{~m} \mathrm{Wm}^{-2}$ (Burkhardt and Kärcher, 2011) based on a comprehensive estimate with a GCM. There are higher estimates in the literature; for example, Stordal et al. (2005) estimated aircraft-induced cloudiness based on observed trends in cirrus coverage and reported an estimated radiative forcing between 10 and $80 \mathrm{~m} \mathrm{Wm}^{-2}$. More recently, Schumann and Graf (2013) reported an estimated contrail radiative forcing of $50 \mathrm{~m} \mathrm{Wm}^{-2}\left(40-80 \mathrm{~m} \mathrm{Wm}^{-2}\right)$ based on the same global aircraft emissions employed in this study.

Capturing such small perturbations through GCM simulations is a major challenge since the variability of the model may be higher than the contrail forcing. Estimates with a free running CAM5 indicate that the detectable (95\% confidence 


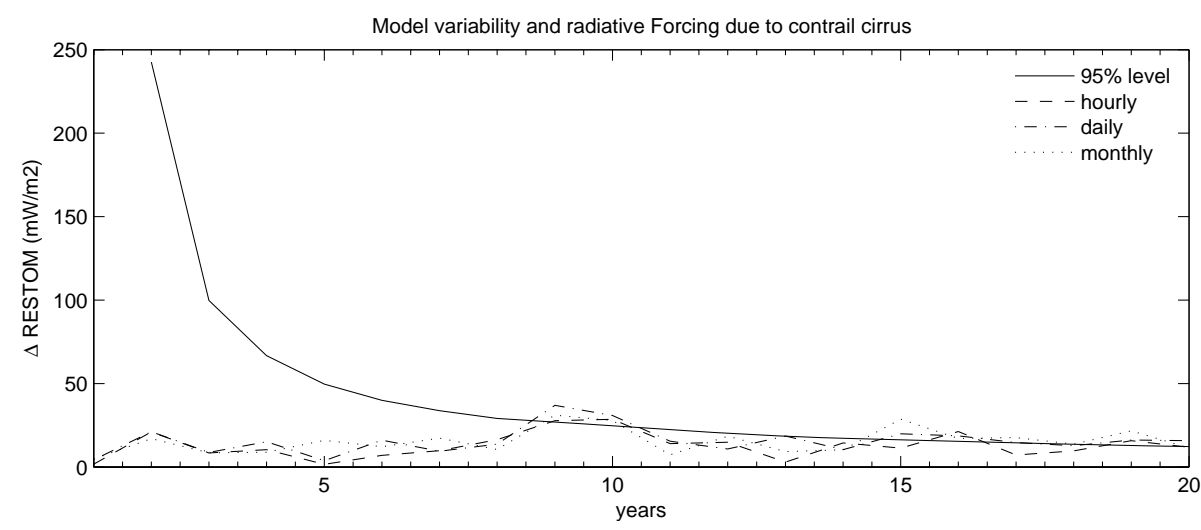

Fig. 1. Radiative forcing due to contrail cirrus: global annual averages using hourly (dashed line), daily (dashed-dotted line), and monthly (dotted line) aircraft emission. Solid line is the significance threshold (95\% confidence interval).

limit for Student's $t$ test) globally averaged radiative flux perturbation at the top of the atmosphere to distinguish any radiative flux perturbation from the model internal variability is $100 \mathrm{~m} \mathrm{Wm}^{-2}$, from a $20 \mathrm{yr}$ simulation. The radiative forcing due to linear contrails and contrail cirrus is very likely to be lower than $100 \mathrm{~m} \mathrm{Wm}^{-2}$, and thus the free-running mode of CAM5 is not an adequate modeling framework for this study.

The model variability of CAM5 is reduced by driving simulations using specified dynamics (CAM5-SD). Using fixed meteorology (imposed pressure, winds and atmospheric and sea surface temperatures), a globally averaged perturbation above $10 \mathrm{~m} \mathrm{Wm}^{-2}$ is statistically significant, based on the $95 \%$ confidence level of Student's $t$ test from a $20 \mathrm{yr}$ simulation with repeating yearly meteorology (see solid curve in Fig. 1). As aircraft emissions are incorporated into CAM5SD simulations, globally averaged radiative fluxes at the top of the atmosphere surpass the model variabilities by the end of $20 \mathrm{yr}$ simulations as shown in Fig. 1.

It is important to note that the use of the SD model does not allow the feedback of aviation impacts on the background meteorology (i.e., pressure, winds and atmospheric and sea surface temperatures). For example, the latent heating due to the formation of contrails is not considered in the SD model, and it could enhance the possibility of contrail formation and the contrail radiative forcing.

In order to address the meteorological and statistical uncertainties and to gain more confidence in our results, we employ an ensemble modeling technique with four ensemble members. Four different yearly meteorological fields are used to drive each of the four members under CAM5-SD in which aircraft emissions are included. These four yearly meteorologies are obtained by performing a free-running CAM5 simulation without aircraft emissions for $4 \mathrm{yr}$. In this study, each of the experiments is repeated four times with the only difference in the background meteorological fields. The spread of the four ensemble members allows us to determine (1) the uncertainty in our calculation of the globally averaged radiative forcing and (2) the significance of local radiative forcing due to the presence of contrails. It is considered significant when the magnitude of local perturbations exceeds two standard deviations of the four ensemble members.

As described previously, larger uncertainties could result from the initial contrail particle size assumed and the cross-sectional area of contrails. In this study, we assume a diameter of $10 \mu \mathrm{m}$ based on contrails aged for 20-30 min (Schröder et al., 2000), and a fairly large cross-sectional area $(300 \mathrm{~m} \times 300 \mathrm{~m})$ for water uptake based on plume model experiments $(\mathrm{H}$. W. Wong at Aerodyne Research, personal communication, 2012).

First, we look at linear contrails. We assume that (1) the lifetime of contrails was equal to the time step of CAM5, $30 \mathrm{~min}$; (2) all contrails vanished at the end of each time step; and (3) contrails did not feed back on the model state. Thus, these diagnostic calculations (calling the microphysics and radiation code twice with and without contrails and aviation $\mathrm{H}_{2} \mathrm{O}$ ) yield an estimate of the radiative forcing for linear contrails at each time step. Results are from four ensemble members of $5 \mathrm{yr}$ averages by repeating its own meteorology annually. These experiments provide an exact estimate of the linear contrail perturbation with no uncertainty as in Fig. 1, since we are performing a diagnostic calculation at each time step, not computing differences in pairs of simulations. Furthermore, aircraft emissions and contrails are assumed to have no impact on model states. The forcing obtained from these online diagnostic calculations is defined as the "instantaneous effect", which represents our best estimate for linear contrail radiative forcing. These initial contrails resemble linear contrails from previous studies in which normalization (Ponater et al., 2002; Rap et al., 2010) or diagnostic lifetime constraint (Burkhardt and Kärcher, 2009) has been made towards observed linear contrail coverage, but they do not refer to the same entity.

The second set of experiments is designed to look at contrail cirrus in which aircraft water vapor emissions were incorporated into the hydrologic cycle of the model without any assumption on the lifetime of contrails. Contrail 

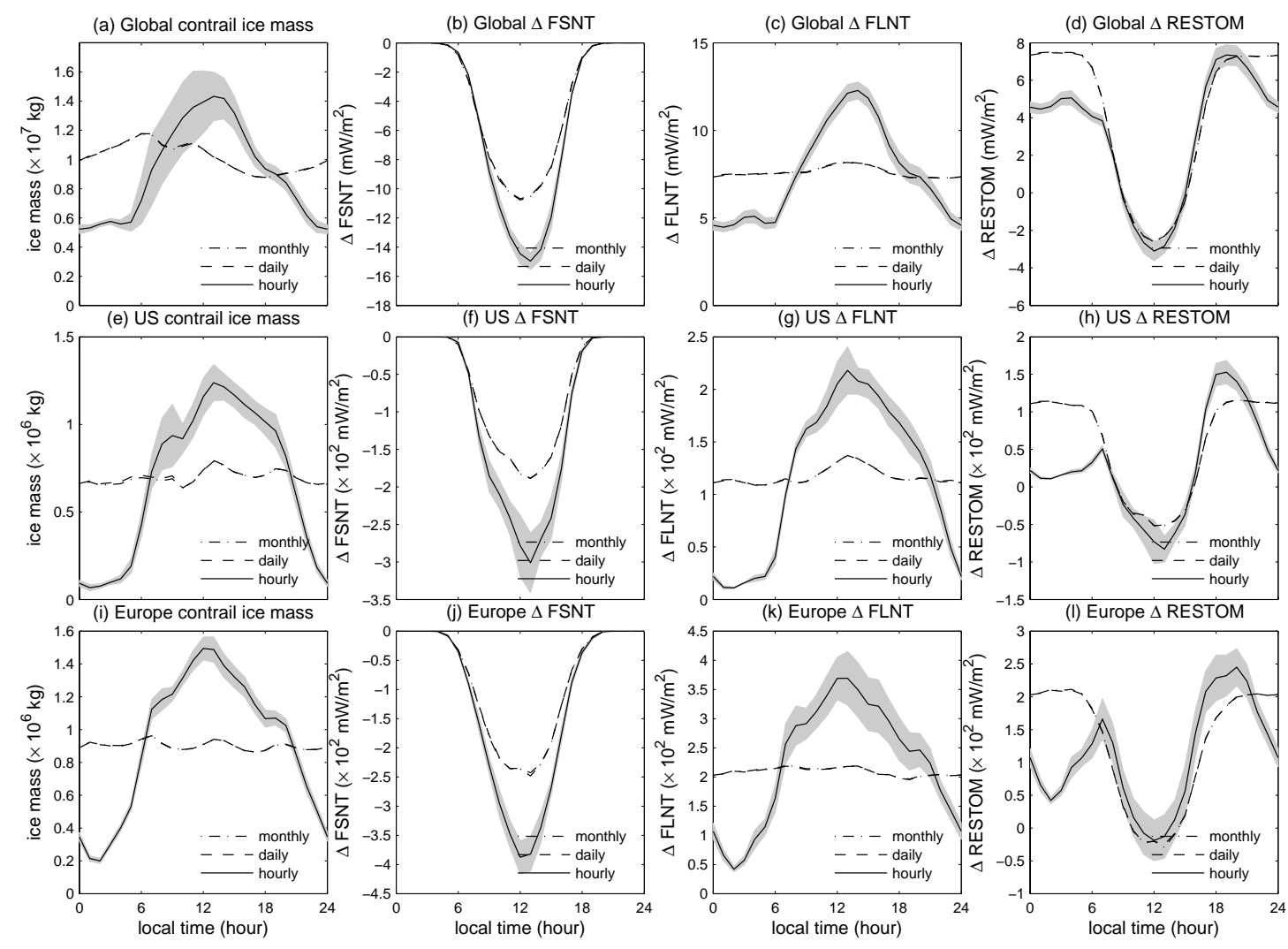

Fig. 2. The diurnal cycle of cloud ice mass, shortwave (FSNT), longwave (FLNT), and net radiative forcing (RESTOM) at the top of atmosphere based on diagnostic calculations by CAM5-SD with hourly, daily, and monthly averaged aircraft emissions over the globe, the eastern US (denoted by the red box in Fig. 4b) and central Europe (denoted by the red box in Fig. 4c) under the instantaneous assumption (linear contrails). The gray shading represents the ensemble mean \pm two standard deviations using hourly aircraft emissions. The model output at each grid point is calibrated to its local time.

initialization is the same as for linear contrails, but the cloud ice in the model is increased, along with ice number and cloud fraction, and the background water vapor is appropriately decreased. The model hydrologic cycle then operates on the contrail as any other cloud and can freely evolve, but it is undifferentiated from other clouds (in contrast to the separate contrail cloud class of Burkhardt and Kärcher, 2011). Linear contrails, once formed, freely evolve during model simulations, depending on the ambient atmospheric temperature and humidity. These experiments are compared with a control simulation without aircraft emissions, and the difference in energy balance at the top of the atmosphere is taken as the radiative forcing due to contrail cirrus. Simulations are run on a $1.9^{\circ} \times 2.5^{\circ}$ latitude-longitude grid with 30 vertical layers driven by meteorology obtained from a free-running CAM5 simulation with fixed climatological sea surface temperatures (SSTs) repeated annually. Results are from four ensemble members of 20-year average differences between a simulation with contrails and aviation water vapor and a simulation without aviation emissions.

\section{Results from CAM5-SD simulations}

Three experiments were conducted with the Aviation Environmental Design Tool (AEDT) emission inventory (Barrett et al., 2010), which is converted to hourly, daily, and monthly data following the procedure described in Chen et al. (2012). Four different yearly meteorologies, from a $4 \mathrm{yr}$ free-running CAM5 simulation, were used, separately, to drive four CAM5-SD ensemble simulations: each member uses a different $1 \mathrm{yr}$ meteorology repeatedly. Uncertainty in the contrail radiative forcing was represented by two standard deviations among these realizations.

The radiative forcing for linear contrails and contrail cirrus is examined. For linear contrails the estimates are based on diagnostic calculations over $5 \mathrm{yr}$, and for contrail cirrus the estimates are based on differences between two simulations over 20 years.

\subsection{Radiative forcing of linear contrails}

For linear contrails, the daily cycle of flights is very important in assessing the radiative effects. As illustrated in 

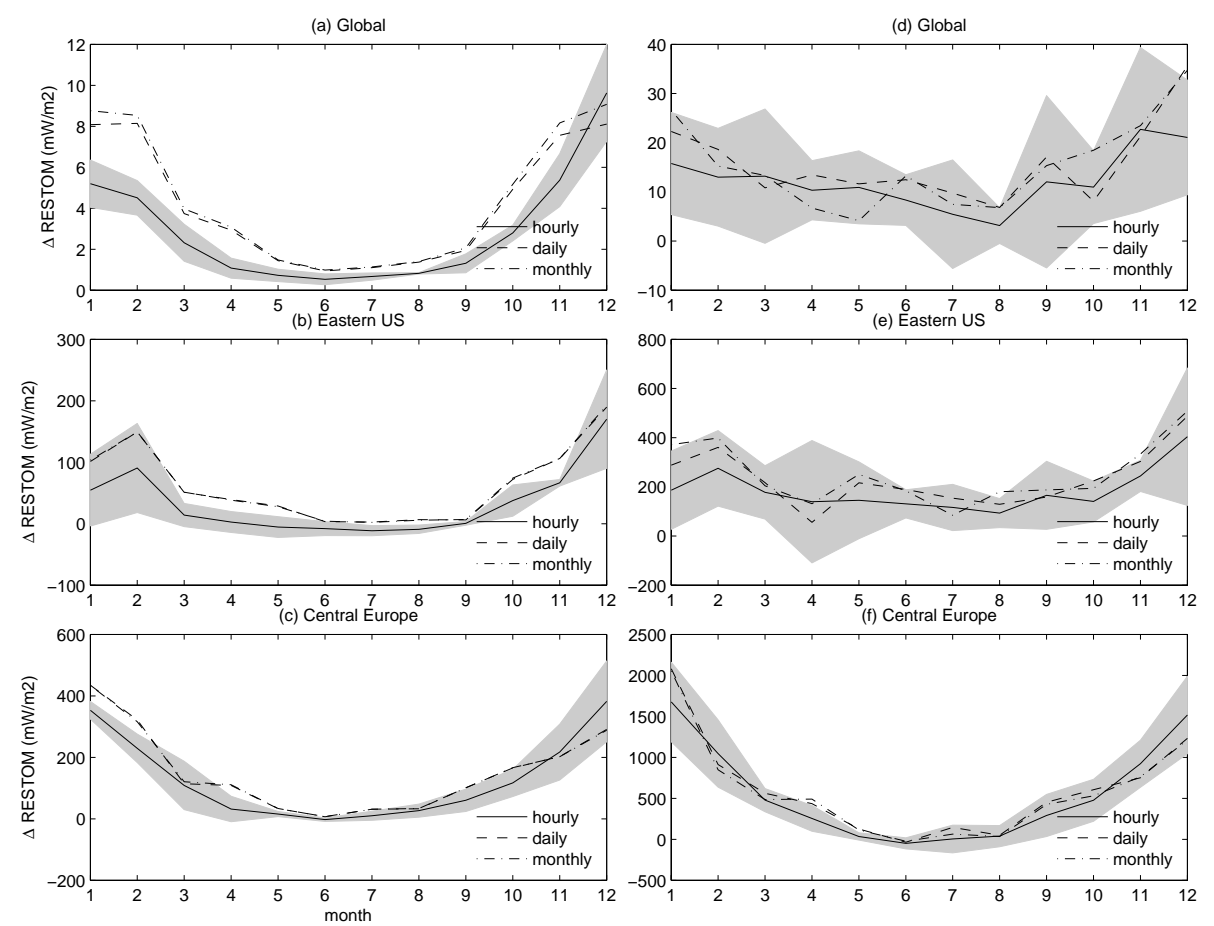

Fig. 3. The monthly averaged net radiative forcing over the globe, eastern US and central Europe by CAM5-SD for linear contrails (panels on the left) and for contrail cirrus (panels on the right) with hourly, daily, and monthly averaged aircraft emissions, denoted by solid, dashed, and dashed-dotted lines. The gray shading represents the ensemble mean \pm two standard deviations using hourly aircraft emissions. Note that the scale on each panel is different.

Fig. 2a and c, when the daily cycle of flights is considered (hourly emissions), the global contrail ice mass exhibits a much stronger diurnal cycle than when using daily or monthly emissions (Fig. 2a). The peak in global contrail ice mass takes place around noon at local time when using hourly emissions, but in the early morning hours when using daily or monthly emissions. The intensity in longwave radiation forcing is found to follow that of the contrail ice mass (Fig. 2a, c). Graf et al. (2012) reported that a strong diurnal cycle could be identified in aviation induced cirrus cover over the North Atlantic flight corridor with two daily peaks at 06:00 and 18:00 UTC that correlate well with air traffic. Over the eastern US and central Europe, the ice mass and forcing of linear contrails also exhibit very similar behavior as in the global average.

The highest number of flights are located in the eastern US and central Europe with more flights taking place during the daytime over the two continents (Chen et al., 2012). The results illustrated in Fig. 2, with model output at each grid point calibrated to its local time, reveal that the peak of the simulated contrail ice mass takes place around noon at local time over both continents. Therefore, averaging aircraft emissions on a monthly or daily basis, which shifts some daytime flights to the nighttime, alters the radiative forcing. The longwave (heating) effect remains approximately the same in the diurnal average (as discussed below), but the shortwave effect is reduced because more contrails occur in darkness when the diurnal cycle is averaged out.

Similar results have been presented in some recent studies (Newinger and Burkhardt, 2012; Schumann and Graf, 2013) that demonstrated that daily air traffic density had an important impact on the contrail radiative forcing. However, it is worth noting that these two studies mainly focused on the diurnal cycle of contrail-cirrus radiative forcing, while illustrated in Fig. 2 for linear contrails.

Contrails induce a positive forcing due to longwave radiation coherent with the diurnal cycle in contrail ice mass with hourly emissions (Fig. 2c). The global longwave positive forcing is found to have a maximum of $12.5 \mathrm{~m} \mathrm{Wm}^{-2}$ at $1 \mathrm{p} . \mathrm{m}$. local time and a minimum of $4.5 \mathrm{~m} \mathrm{Wm}^{-2}$ at 12:00 LT, with a diurnal average of $7.6 \mathrm{~m} \mathrm{Wm}^{-2}$. However, when using daily or monthly averaged aircraft emissions, the longwave forcing shows little diurnal variation. This result seems to suggest that there is little daily variation in the aircraft emissions within each month. Furthermore, this result also implies that the remaining factor in influencing the diurnal cycle of longwave contrail forcing, the ambient atmospheric temperature and humidity, has evidently only a moderate impact. The diurnal average shows almost no variation when using hourly emissions (ensemble mean), daily or monthly emissions. 
(a) Global $\Delta$ RESTOM, ensemble mean $(\mathrm{W} / \mathrm{m} 2)$
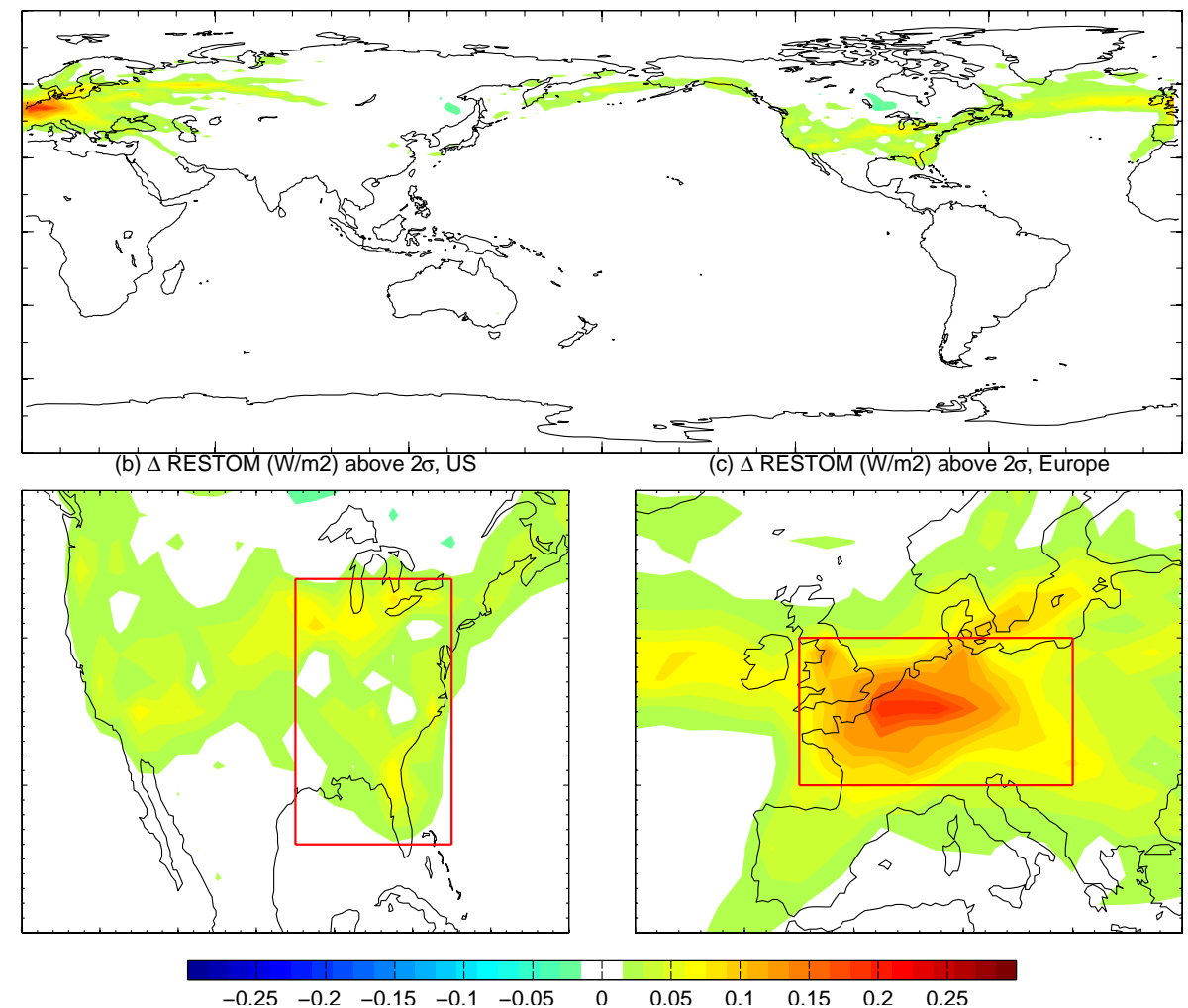

Fig. 4. The spatial distribution of net radiative forcing, in $\mathrm{Wm}^{-2}$, at the top of the atmosphere based on instantaneous calculations by CAM5SD with hourly averaged aircraft emissions. In (b) and (c), only the magnitude of perturbations in each grid cell that is above two standard deviations of the four ensemble members is plotted.

Contrails also produce a negative forcing due to shortwave radiation (Fig. 2b) with a stronger diurnal cycle. The largest negative forcing globally is found at 1 p.m. local time $\left(-15.5 \mathrm{~m} \mathrm{Wm}^{-2}\right.$ using the hourly emissions and $-10 \mathrm{~m} \mathrm{Wm}^{-2}$ for daily or monthly emissions). A window with zero shortwave cooling is found between 8 p.m. and 4 a.m. local time, which is nighttime without solar radiation. The diurnal average in linear contrail shortwave forcing is $-4.6,-3.6$ and $-3.6 \mathrm{~m} \mathrm{Wm}^{-2}$ using hourly, daily and monthly emissions, respectively.

The intensity of contrail shortwave forcing is regulated by the local solar zenith angle. When aircraft emissions are averaged on a daily or monthly basis, the number of daytime flights is reduced over regions where air traffic is mostly concentrated during the daytime (e.g., the eastern US and central Europe), and thus contrail formation during the daytime is decreased, underestimating shortwave forcing. The net effect of linear contrails (Fig. 2d) exhibits a strong diurnal cycle independent of the frequency of aircraft emissions due to the shortwave forcing. Even though the positive longwave forcing peaks around noon, it is mostly canceled out by the negative shortwave forcing. As a result, the net radiative forcing of linear contrails is peaked at both $7 \mathrm{a} . \mathrm{m}$. and $7 \mathrm{p} . \mathrm{m}$. (see Fig. 2d, h, l).
Our first set of simulations reveals that $113 \%$ of the contrail radiative forcing over the eastern US is due to night flights (due to net negative forcing between 6 a.m. and 6 p.m., Fig. 2), $66 \%$ of the contrail radiative forcing over central Europe due to night flights (Fig. 21), and $92 \%$ of the global contrail radiative forcing due to night flights (Fig. 2d). The portion of contrail radiative forcing due to night flights over the globe and over these two regions is higher than the global average attributed to night flights reported by Stuber and Forster (2007) (60\%).

Due to the assumption on the lifetime of linear contrails in our first set of simulations, our estimated radiative forcing for linear contrails is likely to be lower than reality. These "initial contrails" considered in our simulations resemble "linear contrails" from other work, but they are not identical. First, linear contrails in reality could persist much longer than $30 \mathrm{~min}$. Second, our experimental design would miss the lag effect reported in Newinger and Burkhardt (2012) and Schumann and Graf (2013): the maximum in contrail coverage tends to lag the peak of air traffic density by a few hours. 
Table 1. Table of the global mean and regional averages over eastern US and central Europe of shortwave radiative forcing at the top of the atmosphere $(\triangle \mathrm{FSNT})$, longwave radiative forcing at the top of the atmosphere $(\triangle \mathrm{FLNT})$, radiative forcing at the top of the atmosphere ( $\Delta$ RESTOM) due to linear contrails and contrail cirrus by CAM5-SD simulations using hourly/daily/monthly aviation emissions. The uncertainty of the contrail radiative forcing from the simulations with hourly aviation emissions is represented by two standard deviations of the four ensemble members. All units in $\mathrm{m} \mathrm{Wm}^{-2}$.

\begin{tabular}{lccc}
\hline Radiative forcing & Global & Eastern US & Central Europe \\
\hline linear contrail $\Delta$ FSNT & $-4.6 \pm 0.1 /-3.6 /-3.6$ & $-91 \pm 5 /-62 /-62$ & $-119 \pm 4 /-84 /-84$ \\
contrail cirrus $\Delta$ FSNT & $-21.5 \pm 4.9 /-19.3 /-20.4$ & $-431 \pm 42 /-359 /-348$ & $-572 \pm 55 /-430 /-461$ \\
\hline linear contrail $\Delta$ FLNT & $7.6 \pm 0.2 / 7.6 / 7.6$ & $118 \pm 5 / 117 / 117$ & $227 \pm 14 / 209 / 209$ \\
contrail cirrus $\Delta$ FLNT & $33.7 \pm 2 / 35 / 36$ & $616 \pm 21 / 591 / 600$ & $1130 \pm 127 / 1040 / 1043$ \\
\hline linear contrail $\triangle$ RESTOM & $3.1 \pm 0.2 / 4.0 / 4.0$ & $26.7 \pm 5.0 / 55 / 55$ & $108 \pm 12 / 125 / 125$ \\
contrail cirrus $\triangle$ RESTOM & $12.2 \pm 4.0 / 15.7 / 15.5$ & $185 \pm 30 / 232 / 252$ & $577 \pm 81 / 610 / 583$ \\
\hline
\end{tabular}

(a) $\triangle$ RESTOM, ensemble mean $(\mathrm{W} / \mathrm{m} 2)$

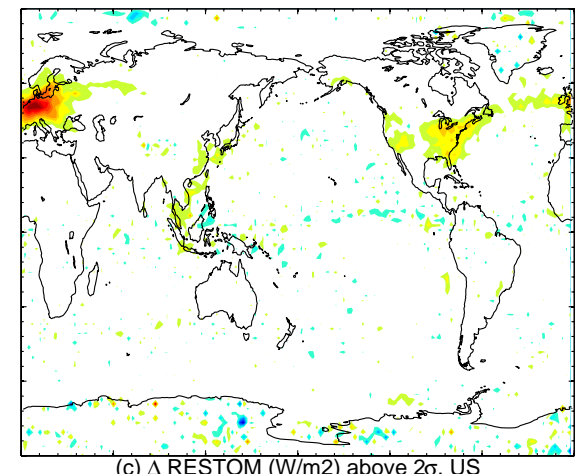

(c) $\Delta$ RESTOM (W/m2) above $2 \sigma, \mathrm{US}$

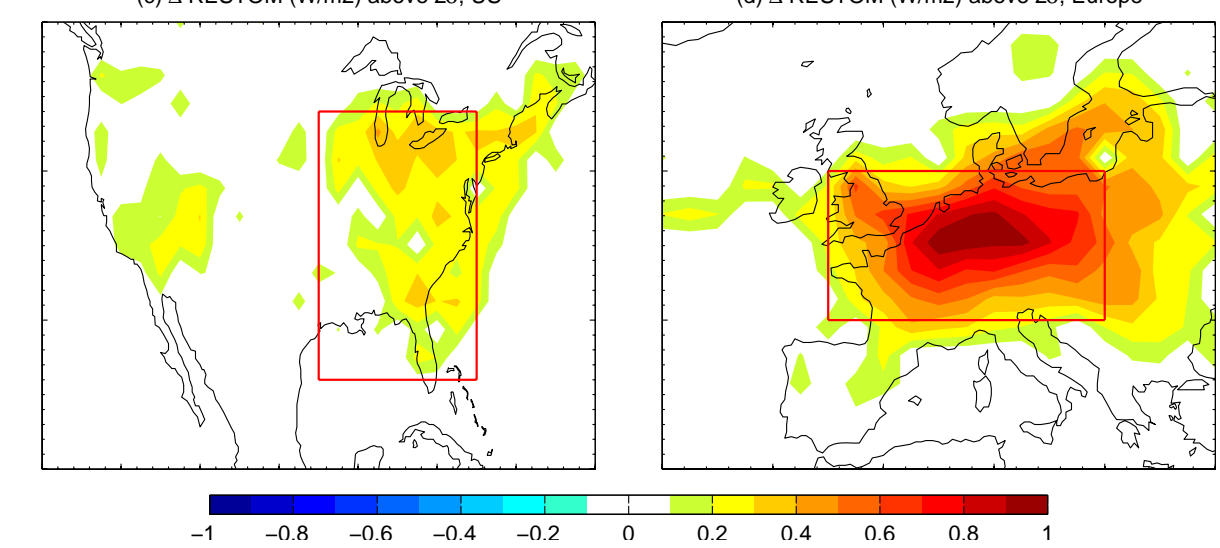

(b) $\triangle$ RESTOM (W/m2) above $2 \sigma$

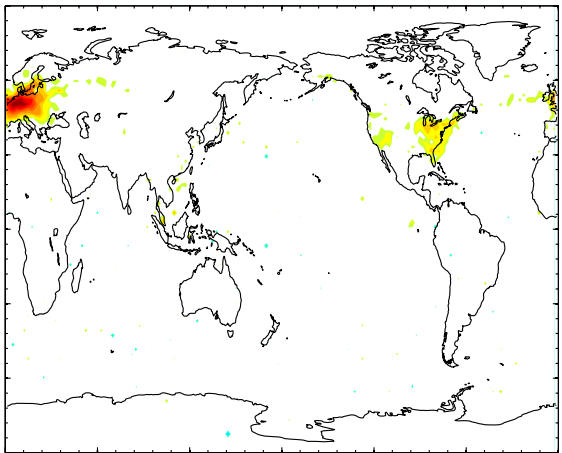

(d) $\triangle$ RESTOM (W/m2) above $2 \sigma$, Europe

Fig. 5. Radiative forcing due to contrail cirrus: map of the ensemble mean by using hourly emissions in $\mathrm{Wm}^{-2}$. (b) The magnitude of perturbations in each grid cell in (a) that is above two standard deviations of the four ensemble members.

\subsection{Monthly averaged contrail radiative forcing}

Both sets of simulations exhibit a consistent seasonal cycle with higher positive radiative forcing during the Northern Hemisphere winter months (Fig. 3), which is consistent with atmospheric conditions in the UTLS and more favorable for contrail formation and higher ice mass during the winter than in the summer (Chen et al., 2012).

In the first set of simulations, significant differences in the global radiative forcing are introduced when using hourly, daily, or monthly averaged aircraft emissions (Table 1). The simulation with hourly aircraft emissions produces the lowest radiative forcing throughout the year (Fig. 3a, b, c). Hourly aircraft emissions accurately represent the daily cycle of flights and capture the strong daytime negative shortwave forcing, thus resulting in weaker net radiative forcing.

The effect of contrail cirrus is greater than that of linear contrails. The monthly averaged forcing of contrail cirrus is roughly four times that of linear contrails (Table 1). Because the integrated effects allow for longer contrail lifetimes, and 
(a) $\Delta$ optical depth due to linear contrails (grid-box average)

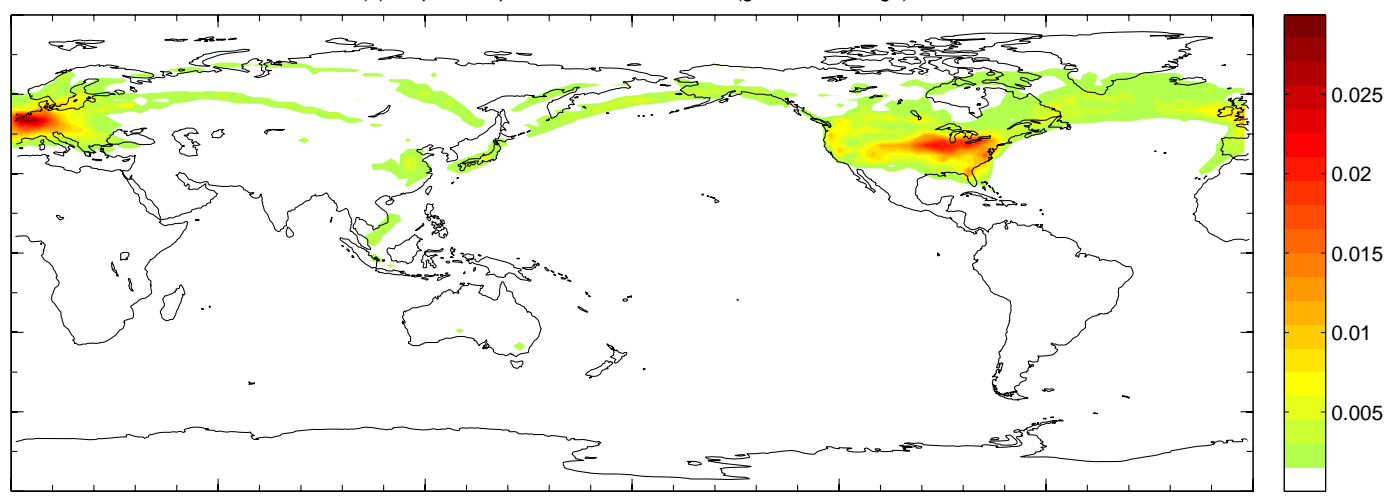

(b) cloud fraction due to linear contrails (\%)

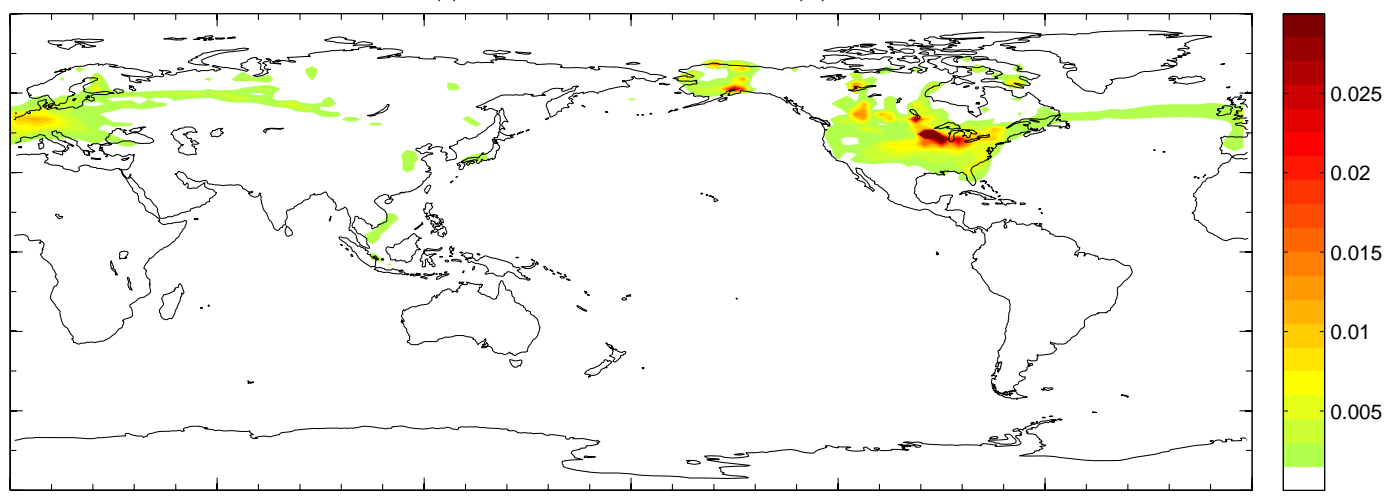

Fig. 6. The spatial distribution of column sum of grid-box (a) optical depth and (b) cloud fraction due to linear contrails based on a 1 yr CAM5 simulation using hourly emissions.

water vapor emission impacts on natural cirrus, the effect of contrail cirrus is less sensitive to the frequency of aircraft emissions input (hourly, daily, monthly, see Fig. 3d, e, f).

Table 1 has uncertainty reflecting meteorological variability. Uncertainties in contrail radiative forcing could be also induced by parametric assumptions made in our contrail initialization. For example, linear contrail radiative forcing increases by a factor of 9 when the particle diameter is reduced from 10 to $5 \mu \mathrm{m}$,which almost scales linearly with the particle number concentration. The contrail radiative forcing decreases by a factor of 2.5 when the cross-sectional area is reduced to $100 \mathrm{~m} \times 100 \mathrm{~m}$. Based on Schröder et al. (2000), a diameter of $5 \mu \mathrm{m}$ in particle size for young contrails (20$30 \mathrm{~min}$ ) is too small. But a diameter of $7.5 \mu \mathrm{m}$ can result in an increase in the particle number, and hence radiative forcing (scaling linearly with number concentration) by a factor of 2.5. Therefore, the uncertainty in Table 1 should be multiplied by a factor of 2.5 to account for the parametric uncertainty, which is the uncertainty stated in the conclusion section. Additional uncertainties in contrail radiative forcing estimates could further result from the contrail particle shape. The sensitivity of particle shape on the contrail radiative forcing has been investigated in several studies (Marquart et al., 2003; Rap et al., 2010; Markowicz and Witek, 2011) that sug- gested that the assumption of a spherical shape for contrail ice particles could result in a less intense shortwave forcing.

\subsection{Annual global and regional contrail radiative forcing}

A map of the radiative forcing of linear contrails using hourly aircraft emissions (Fig. 4) indicates regions with substantial radiative forcing located along flight tracks over North America and Europe and the North Atlantic. Similar features are also found in the effect of contrail cirrus as shown in Fig. 5a and $b$. The global average radiative forcing of linear contrails at the top of the atmosphere simulated by CAM5$\mathrm{SD}$ ranges from 3.1 to $4.0 \mathrm{~m} \mathrm{Wm}^{-2}$ (Table 1), depending on whether hourly, daily or monthly emissions are used. The forcing is $29 \%$ higher when using the monthly emissions compared with that using the hourly emissions. The net radiative forcing associated with contrail cirrus increases only $25 \%$ when using daily, instead of hourly, emissions (12.4 to $15.5 \mathrm{~m} \mathrm{Wm}^{-2}$ in Table 1). Therefore, the effect of contrail cirrus is less sensitive to the daily cycle of flights than that of linear contrails.

The global average may not be a good measure of the magnitude of contrail impact, especially within high air traffic corridors. The regional mean radiative forcing can reach 27 
and $108 \mathrm{~m} \mathrm{Wm}^{-2}$ for eastern US and central Europe, respectively (boxes in Fig. 4b, c, as listed in Table 1 with hourly emissions). Similarly, even though contrail cirrus only produces a global forcing of $12.4 \mathrm{~m} \mathrm{Wm}^{-2}$, the regional mean is roughly 200 and $600 \mathrm{~m} \mathrm{Wm}^{-2}$, respectively. The local effect is as large as $400 \mathrm{~m} \mathrm{Wm}^{-2}\left(0.4 \mathrm{Wm}^{-2}\right)$ over much of the northeastern US (Fig. 5c), and up to $1000 \mathrm{~m} \mathrm{Wm}^{-2}$ $(1 \mathrm{Wm}-2)$ over the highest air traffic regions of western Europe (Fig. 5d).

The regional impact of contrail cirrus was also investigated in some recent studies. Burkhardt and Kärcher (2011) reported that radiative forcing of more than $300 \mathrm{~m} \mathrm{Wm}^{-2}$ could be induced by contrail cirrus over the eastern US and central Europe. Newinger and Burkhardt (2012) found that the contrail radiative forcing ranged between 100 and $300 \mathrm{~m} \mathrm{Wm}^{-2}$ over the US and between 200 and $500 \mathrm{~m} \mathrm{Wm}^{-2}$ over western Europe (see their Fig. 3). These numbers are overall consistent with our simulations (see Table 1). However, Schumann and Graf (2013) reported a longwave radiative forcing of $720 \mathrm{~m} \mathrm{Wm}^{-2}$ over the North Atlantic area, which is higher than our estimated longwave forcing over the eastern US (630 $\mathrm{m} \mathrm{Wm}^{-2}$ using hourly emission, see Table 1$)$ where air traffic density is even higher.

\section{Discussions and conclusions}

Our simulations indicate that linear contrail radiative forcing is very sensitive to the frequency of aircraft emissions incorporated into CAM5-SD. Without the consideration of the daily cycle of flights, the simulations failed to capture the pronounced diurnal cycle of linear contrail formation and substantially reduced strong negative shortwave forcing in the afternoon hours leading to a $29 \%$ overestimate of contrail radiative forcing. Thus, it is essential to incorporate aircraft emission of high frequency into GCM simulations to produce credible assessments for linear contrail radiative forcing. Other factors that can strongly influence the estimate of linear contrail radiative forcing include the ice particle size, the cross-sectional area, and the lifetime of contrails.

Since there is no distinct cloud type for contrails in CAM5, our first set of simulations represents our best estimate for the linear contrail radiative forcing. Our methodology is to compute the fractional volume associated with linear contrails within each grid cell at every time step based on the contrail ice mass and the empirical contrail in-cloud ice water content. This fractional volume enters the model state as additional cloud fraction to the background clouds, so do the extra ice particles due to contrails. CAM5 then uses the information to calculate the grid-box averaged optical depth of all grid cells. The column sums of additional grid-box averaged optical depth and cloud fraction (assuming zero overlap) due to linear contrails are illustrated in Fig. 6. The simulation indicates that the presence of linear contrails can enhance op-
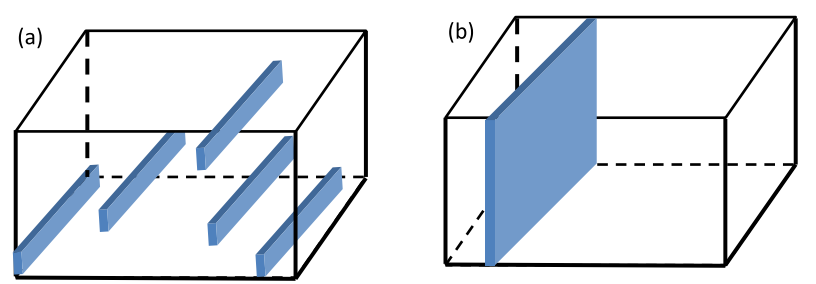

Fig. 7. A schematic showing (a) a scenario of five linear contrails within a model grid cell and (b) how the radiative transfer scheme of CAM5 treats the scenario in (a).

tical depth by 0.02 to 0.03 and cloud fraction by $0.03 \%$ and $0.01 \%$ over the eastern US and central Europe, respectively.

One important factor in controlling the uncertainties in contrail radiative forcing estimates is contrail optical depth (Stuber and Forster, 2007; Kärcher et al., 2010; Frömming et al., 2011). By the formulation of CAM, the in-cloud optical depth is simply the grid-box optical depth divided by the corresponding cloud fraction. However, such conversion of in-cloud optical depth assumes a uniform vertical cloud structure within each grid cell. Since the vertical grid spacing around the UTLS region in CAM5 is roughly $1 \mathrm{~km}$, this conversion implies that the physical depth of linear contrails is $1 \mathrm{~km}$, which is unrealistic and implies that the in-cloud optical depth for linear contrails simulated by CAM5 is on the order of 100 (estimated from Fig. 6). The issue with such conversion is illustrated in Fig. 7: in reality, the distribution might be closer to Fig. 7a, but the model radiative transfer scheme treats the contrails within the grid cell as in Fig. $7 \mathrm{~b}$. Therefore, in order to obtain an accurate estimate of in-cloud optical depth for linear contrails from our simulations, information about the physical depth of linear contrails would be needed. For example, if the physical depth of the clouds in the UTLS is $100 \mathrm{~m}$, the cloud coverage would be up to 10 times their cloud fraction and the in-cloud optical depth would be reduced by a factor of 10 from the formulation of the model. Thus, when dealing with physically thin clouds relative to the vertical grid spacing, cloud fraction in the model cannot be used as cloud coverage.

The most important factor that regulates the contrail radiative forcing in each grid cell of a GCM is the grid-box contrail optical depth. Listed in Table 2 is the estimated averaged grid-box optical depth, defined as the product of in-cloud optical depth and the averaged cloud cover, associated with linear contrails from four previous studies and our work. It is found that the averaged grid-box optical depth in this study is higher than previous studies. Recall that the definition of linear contrails is different from previous studies. Since in this study we only consider fresh contrails with a lifetime of $30 \mathrm{~min}$, the in-cloud optical depth is likely to be much higher than more mature linear contrails, mainly due the smaller ice particle size. However, the in-cloud ice water content for linear contrails decreases as they age, which will enhance the 
Table 2. The table of in-cloud optical depth $(\tau)$, coverage, and shortwave (SW), longwave (LW), net (NET) radiative forcing (RF), in $\mathrm{m} \mathrm{Wm}^{-2}$, associated with linear contrails from five studies. The averaged grid-box contrail optical depth is estimated by the product of in-cloud contrail optical depth and average contrail coverage. CAM5 does not produce "coverage" and in-cloud $\tau$ as described in the text, only cloud fraction.

\begin{tabular}{lcccccc}
\hline Reference & In-cloud $\tau$ & Coverage & Grid-box $\bar{\tau}$ & $\mathrm{RF}_{\mathrm{SW}}$ & $\mathrm{RF}_{\mathrm{LW}}$ & $\mathrm{RF}$ \\
\hline Myhre and Stordal (2001) & 0.3 & $0.09 \%$ & $2.7 \times 10^{-4}$ & -11.0 & +20.0 & +9.0 \\
Stuber and Forster (2007) & 0.1 & $0.04 \%$ & $4 \times 10^{-5}$ & -1.35 & +3.34 & +2.0 \\
Rap et al. (2010) & 0.1 & $0.055 \%$ & $5.5 \times 10^{-5}$ & -2.4 & +6.3 & +3.9 \\
Frömming et al. (2011) & 0.08 & $0.09 \%$ & $7.2 \times 10^{-5}$ & -2.5 & +9.3 & +6.8 \\
This work & N/A & N/A & $4.2 \times 10^{-4}$ & -4.6 & +7.6 & +3.1 \\
\hline
\end{tabular}

(a) $\Delta$ IWP $(g / m 2)$ due to contrail cirrus

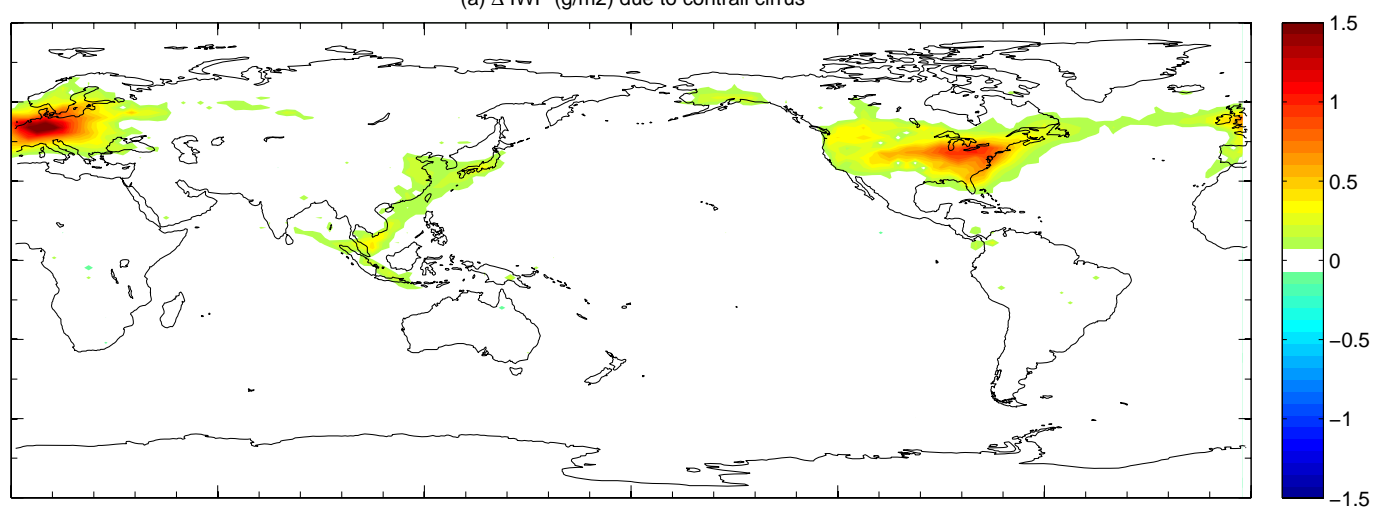

(b) $\Delta$ optical depth due to contrail cirrus

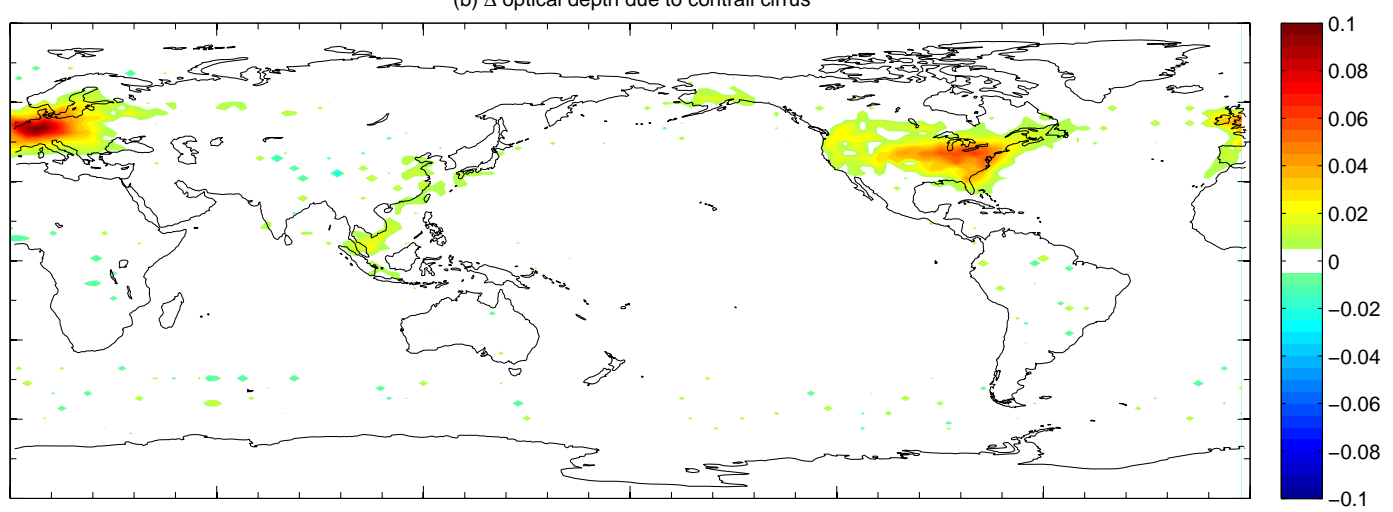

Fig. 8. The spatial distribution of (a) ice water path in $\mathrm{g} \mathrm{m}^{-2}$ and (b) column sum of grid-box optical depth due to contrail cirrus. The results are based on the ensemble mean of the $20 \mathrm{yr}$ simulations using hourly aircraft emissions, and only perturbations above two standard deviations of the ensemble are plotted.

contrail coverage. Unterstrasser and Gierens (2010) (Fig. 1) showed that these two competing effects nearly cancel each other.

Frömming et al. (2011) found a nearly linear relationship between contrail radiative forcing and contrail optical depth. In our two sets of simulations for the radiative forcing for linear contrails and contrails cirrus, we found a very similar behavior. The ice water content and optical depth associated with contrail cirrus by the ensemble mean using hourly emissions can be seen in Fig. 8. The most pronounced simulated contrail optical depth (Fig. 8b) is confined over the eastern
US and central Europe up to 0.06 and 0.1, respectively, which is a factor of 3-4 larger than that of linear contrails (Fig. 6a). The regional forcing (Figs. 4 and 5) scales almost linearly with the optical depth.

Compared with several previous studies, the perturbation optical depth due to contrail cirrus simulated by CAM5 is more confined over regions with high air traffic. For example, the result presented by Burkhardt and Kärcher (2011) was more widespread with largest contrail-cirrus optical depth perturbations in the tropics. This is one reason why our 
estimate in contrail radiative forcing is lower than several previous studies.

Our first set of simulations shows one daily minimum around noon in the shortwave radiative forcing in the diurnal cycle (see Fig. 2), but some previous studies (Meerkötter et al., 1999; Dietmüller et al., 2008) found two daily minima at dawn and dusk. Markowicz and Witek (2011); Forster et al. (2012), and Schumann et al. (2012) demonstrated that a low solar zenith angle could enhance the negative shortwave forcing under the assumption of various crystal shapes for linear contrails. In CAM5, however, contrails are treated in the same way as other ice clouds whose particle shape recipe was assumed to be a mixture of various shapes and sizes (Neale et al., 2010). Thus, we believe that the diurnal cycle of the contrail shortwave forcing can be very sensitive to the assumed shape recipe for contrails. This is left for future investigations since a distinct cloud type and particle shape recipe for contrails in CAM5 is required.

The contrail cirrus simulations, however, have lower sensitivity to the diurnal cycle of aircraft emissions. The overestimate by ignoring a diurnal cycle was only $25 \%$ for contrail cirrus. Consequently, using monthly averaged aircraft emissions in GCM simulations could produce reasonable contrail cirrus radiative forcing but with a warm (high) bias to the estimates.

Contrail cirrus radiative forcing is roughly a factor of 4 larger than the effect of linear contrails. Assuming a linear relation between the forcing and the lifetime of contrails, the results imply that contrails last $2 \mathrm{~h}$ on average, which is reasonable compared with observations. The overall effect of contrail cirrus by CAM5 is estimated to be $13 \pm 10 \mathrm{~m} \mathrm{Wm}^{-2}$ (from Table 1 with the multiplication of 2.5 to account for parametric uncertainty), lower than other recent estimates by Burkhardt and Kärcher (2011).

To put these results in perspective, contrail cirrus is a significant fraction of the global average aviation $\mathrm{CO}_{2}$ radiative forcing of about $30 \mathrm{~m} \mathrm{Wm}^{-2}$ (Lee et al., 2010). It is also important to note that the $200-600 \mathrm{~m} \mathrm{Wm}^{-2}$ over Europe is a significant fraction of the total anthropogenic radiative forcing from long-lived greenhouse gases. Though the global effect of contrails is insignificant, the regional concentration of forcing might be important. One of the advantages of our method is that the contrail parameterization can be run inside a full Earth system model with a coupled ocean to ascertain any effects on the surface temperature. The regional effect on the surface temperature is a subject of future investigation.

Acknowledgements. This work was funded by the FAA's ACCRI program under award DTRT57-10-C-10012. Computing resources were provided by the Climate Simulation Laboratory at National Center for Atmospheric Research (NCAR) Computational and Information Systems Laboratory. NCAR is sponsored by the US National Foundation.

Edited by: P. Jöckel

\section{References}

Appleman, H.: The formation of exhaust condensation trails by jet aircraft, B. Am. Meteor. Soc., 34, 14-20, 1953.

Barrett, S., Prather, M., Penner, J., Selkirk, H., Balasubramanian, S., Dopelheuer, A., Fleming, G., Gupta, M., Halthore, R., Hileman, J., Jacobson, M., Kuhn, S., Lukachko, S., Miake-Lye, R., Petzold, A., Roof, C., Schaefer, M., Schumann, U., Waitz, I., and Wayson, R.: Guidance on the use of AEDT gridded aircraft emissions in atmospheric models, version 2.0, Tech. rep., Federal Aviation Administration, 2010.

Burkhardt, U. and Kärcher, B.: Process-based simulation of contrail cirrus in a global climate model, J. Geophys. Res., 114, D16201, doi:10.1029/2008JD011491, 2009.

Burkhardt, U., Kärcher, B., and Schumann, U.: Global modeling of the contrail and contrail cirrus climate impact, B. Am. Meteor. Soc., 479-483, 2010.

Burkhardt, U. and Kärcher, B.: Global radiative forcing from contrail cirrus, Nature, 1, doi10.1038/NCLIMATE1068, 2011.

Chen, C.-C., Gettelman, A., Craig, C., Minnis, P., and Duda, D. P.: Global contrail coverage simulated by CAM5 with the inventory of 2006 global aircraft emissions, J. Adv. Model. Earth Syst., 4, M04003, doi:10.1029/2011MS000105, 2012.

Dietmüller, S., Ponater, M., Sausen, R., Hoinka, K.-P., and Pechtl, S.: Contrails, natural clouds, and diurnal temperature range, J. Clim., 21, 5061-5075, doi:10.1175/2008JCLI2255.1, 2008.

Duda, D. P., Minnis, P., Khlopenkov, K., Chee, T. L., and Boeke, R.: Estimation of 2006 Northern Hemisphere contrail coverage using MODIS data, Geophys. Res. Lett., 40, 612-617, doi:10.1002/grl.50097, 2013.

Forster, L., Emde, C., Mayer, B., and Unterstrasser, S.: Effects of three-dimensional photon transport on the radiative forcing of realistic contrails, J. Atmos. Sci., 69, 2243-2255, 2012.

Frömming, C., M. Ponater, U. Burkhardt, A. Stenke, S. Pechtl, and R. Sausen, 2011: Sensitivity of contrail coverage and contrail radiative forcing to selected key parameters. Atmos. Environ., 45, 1483-1490.

Gettelman, A., Fetzer, E. J., Irion, F. W., and Eldering, A.: The global distribution of supersaturation in the upper troposphere, J. Climate, 19, 6089-6103, 2006.

Gettelman, A., Liu, X., Ghan, S. J., Morrison, H., Park, S., Conley, A. J., Klein, S. A., Boyle, J., Mitchell, D. L., and Li, J.-L.: Global simulations of ice nucleation and ice supersaturation with an improved cloud scheme in the Community Atmosphere Model, J. Geophys. Res., 115, D18216, doi:10.1029/2009JD013797, 2010.

Graf, K., Schumann, U., Mannstein, H., and Mayer, B.: Aviation induced diurnal North Atlantic cirrus cover cycle, Geophys. Res. Lett., 39, L16804, doi:10.1029/2012GL052590, 2012.

Kärcher, B., Burkhardt, U., Ponater, M., and Frömming, C.: Importance of representing optical depth variability for estimates of global line-shaped contrail radiative forcing, Proc. Natl. Acad. Sci. USA, 107, 19181-19184, doi:10.1073/pnas.1005555107, 2010.

Lee, D. S., Fahey, D. W., Forster, P. M., Newton, P. J., Wit, R. C. N., Lim, L. L., Owen, B., and Sausen, R.: Aviation and global climate change in the 21st century, Atmos. Environ., 43, 35203537, 2009.

Lee, D. S., Pitari, G., Grewe, V., Gierens, K., Penner, J. E., Petzold, A., Prather, M. J., Schumann, U., Bais, A., Bernsten, T., Iachetti, 
D., Lim, L. L., and Sausen, R.: Transport impacts on atmosphere and climate: Aviation. Atmos. Environ., 44, 4678-4734, 2010.

Liu, X., R. C. Easter, Jr, S. J. Ghan, R. A. Zaveri, P. J. Rasch, X. Shi, J. F. Lamarque, A. Gettelman, H. Morrison, F. Vitt, A. Conley, S. Park, R. Neale, C. Hannay, A. M. Ekman, P. Hess, N. Mahowald, W. D. Collins, M. J. Iacono, C. S. Bretherton, M. G. Flanner and D. Mitchell, 2012: Toward a minimal representation of aerosols in climate models: description and evaluation in the Community Atmosphere Model CAM5. Geosci. Model Dev., 5, 709-739, doi:10.5194/gmd-5-709-2012, 2012.

Markowicz, K. and Witek, M.: Simulations of contrail optical properties and radiative forcing for various crystal shapes, J. Climate, 50, 1740-1754, doi:10.1175/2011JAMC2618.1, 2011.

Marquart, S. and Mayer, B.: Towards a reliable GCM estimation of contrail radiative forcing, Geophys. Res. Lett., 29, 1179, doi:10.1029/2001GL014075, 2002.

Marquart, S., Ponater, M., Mager, F., and Sausen, R.: Future development of contrail cover, optical depth and radiative forcing: impacts of increasing air traffic and climate change, J. Climate, 16, 2890-2904, 2003.

Meerkötter, R., Schumann, U., Doelling, D. R., Minnis, P., Nakajima, T., and Tsushima, Y.: Radiative forcing by contrails, Ann. Geophys., 17, 1080-1094, doi:10.1007/s00585-999-10807, 1999.

Minnis, P., Young, D. F., Garber, D. P., Nguyen, L., Smith, W. L. J., and Palikonda, R.: Transformation of contrails into cirrus during SUCCESS, Geophys. Res. Lett., 25, 1157-1160, 1998.

Minnis, P., Ayers, J. K., Palikonda, R., and Phan, D.: Contrails, cirrus trends, and climate, J. Clim., 17, 1671-1685, 2004.

Morrison, H. and Gettelman, A.: A new two-moment bulk stratiform cloud microphysics scheme in the Community Atmospheric Model (CAM3), Part I: description and numerical tests, J. Climate, 21, 3642-3659, 2008.

Myhre, G. and Stordal, F.: On the tradeoff of the solar and thermal infrared radiative impact of contrails, Geophys. Res. Lett., 28, 3119-3122, 2001.

Neale, R. B., Chen, C.-C., Gettelman, A., Lauritzen, P. H., Park, S., Williamson, D. L., Conley, A. J., Garcia, R., Kinnison, D., Lamarque, J.-F., Marsh, D., Mills, M., Smith, A. K., Tilmes, S., Vitt, F., Morrison, H., Cameron-Smith, P., Collins, W. D., Iacono, M. J., Easter, R. C., Ghan, S. J., Liu, X., Rasch, P. J., and Taylor, M. A.: Description of the NCAR Community Atmosphere Model (CAM 5.0), NCAR Technical Note, (http://www.cesm.ucar.edu/models/cesm1.0/cam/docs/ description/cam5_desc.pdf), 2010.

Newinger, C. and U. Burkhardt: Sensitivity of contrail cirrus radiative forcing to air traffic scheduling, J. Geophys. Res., 117, D10205, doi:10.1029/2011JD016736, 2012.

Ponater, M., S. Marquart, and R. Sausen: Contrails in a comprehensive global climate model: parameterization and radiative forcing results, J. Geophys. Res., 107, 4164, doi:10.1029/2001JD000429, 2002.
Rädel, G. and Shine, K. P.: Radiative forcing by persistent contrails of its dependence on cruise altitude, J. Geophys. Res., 113, D07105, doi:10.1029/2007JD009117, 2008.

Rap, A., Forster, P. M., Jones, A., Boucher, O., Haywood, J. M., Bellouin, N., and De Leon, R. R.: Parameterization of contrails in the UK Met Office Climate Model, J. Geophys. Res., 115, D10205, doi:10.1029/2009JD012443, 2010.

Schmidt, E.: Die Entstehung von Eisnebel aus den Auspuffgasen von Flugmotoren, in: Verlag R. Oldenbourg, Schriften der Deutschen Akademie der Luftfahrtforschung, 44, 1-15, 1941.

Schröder, F., B. Kärcher, C. Duroure, J. Strom, A. Petzold, J.-F. Gayet and B. Strauss, 2000: On the transition of contrails into cirrus clouds, J. Atmos. Sci., 57, 464-480.

Schumann, U. and Wendling, P.: Determination of contrails from satellite data and observational results, Proc. of a DLR Intern. Coll., 15/16 November 1990, Lecture Notes in Engineering, 60, Spinger-Verlag, Berlin, 138-153, 1990.

Schumann, U.: On conditions for contrail formation from aircraft exhausts, Meteorol. Z., 5, 4-24, 1996.

Schumann, U.: Contrail cirrus, edited by: Lynch, D. K., Sassen, K., Starr, D., and Stephens, G., Cirrus, 231-255, Oxford University Press, 2002.

Schumann, U., Mayer, B., Graf, K., and Mannstein, H.: A parameteric radiative forcing model for contrail cirrus, J. Appl. Meteor., 51, 1391-1406, 2012

Schumann, U. and Graf, K.: Aviation-induced cirrus and radiation changes at diurnal timescales, J. Geophys. Res., 118, 2404 2421, doi:10.1002/jgrd.50184, 2013.

Stephens, G. L. and P. J. Webster, 1981: Clouds and climate: sensitivity of simple systems, J. Atmos. Sci., 38, 235-247.

Stordal, F., Myhre, G., Stordal, E. J. G., Rossow, W. B., Lee, D. S., Arlander, D. W., and Svendby, T.: Is there a trend in cirrus cloud cover due to aircraft traffic?, Atmos. Chem. Phys., 5, 2155-2162, doi:10.5194/acp-5-2155-2005, 2005.

Stuber, N., Forster, P., Rädel, G., and Shine, K.: The importance of the diurnal and annual cycle of air traffic for contrail radiative forcing. Nature, 441, 864-867, doi:10.1038/nature04877, 2006.

Stuber, N. and Forster, P.: The impact of diurnal variations of air traffic on contrail radiative forcing, Atmos. Chem. Phys., 7, 3153-3162, doi:10.5194/acp-7-3153-2007, 2007.

Unterstrasser, S. and Gierens, K.: Numerical simulations of contrail-to-cirrus transition - Part 2: Impact of initial ice crystal number, radiation, stratification, secondary nucleation and layer depth, Atmos. Chem. Phys., 10, 2037-2051, doi:10.5194/acp-102037-2010, 2010. 